drug addicts, and died at home. Typically, the deceased took several different (prescribed and non-prescribed) drugs with ecstasy; the large number of people who also took opiates seems surprising but confirms previous findings and may explain why a high proportion of the victims were known to services. ${ }^{4}$ People may have taken ecstasy with other drugs to modulate the effects-ecstasy had, at least, a facilitating role in causing death. A small proportion of people $(6 / 81$; $7 \%$ ) died after taking only ecstasy-a previously doubted possibility. ${ }^{5}$ Toxicological tests could detect all drugs that had been taken in the 2-3 days before death and gave only limited information about which drugs had been taken on the last occasion. Deaths related to ecstasy occurred in two clusters (urban industrial areas in southeast and northern England); people died mostly at party times (weekends, summer, and at New Year).

Information about the incidence of taking ecstasy and other drugs and amounts taken is unfortunately lacking; the database of the National Programme on Substance Abuse Deaths (which is being extended to Northern Ireland and Scotland) will collect more information in future-for example, the concentration of individual drugs in tissues-to obtain a better understanding of the role of other drugs in deaths related to taking ecstasy.

Contributors: FS wrote the manuscript and coordinated the study. AO, LW, MP, and JC collected data and interpreted the results. AHG participated in interpreting the results. FS is guarantor.

Funding: No additional funding.

Competing interests: None declared.

1 European Monitoring Centre for Drug and Drug Addiction. Annua report on the state of drugs problems in the European Union. Lisbon: EMCDDA, 2001.

2 Gore SM. Fatal uncertainty: death-rate from use of ecstasy or heroin. Lancet 1999:354:1265-6.

3 Ghodse AH, Oyefeso A, Webb L, Schifano F, Pollard M, Jambert-Gray R, et al. Drug-related deaths as reported by coroners in England and Wales. London: European Centre for Addiction Studies, 2002. (Annual review 2001 and np-SAD surveillance report No 9.)

4 Schifano F. Potential human neurotoxicity of MDMA ("ecstasy"): subjective self-reports, evidence from an Italian drug addiction centre and clinical case studies. Neuropsychobiology 2000;42:25-33.

5 Giroud C, Augsburger M, Sadeghipour F, Varesio E, Veuthey JL, Rivier I. Ecstasy: the status in French-speaking Switzerland: composition of seized Ecstasy: the status in French-speaking Switzerland: composition of seized
drugs, analysis of biological specimens and short review of its pharmacodrugs, analysis of biological specimens and short review of its pharma
logical action and toxicity. Schweiz Rundsch Med Prax 1997;86:510-23. (Accepted 21 June 2002)

\title{
Recent changes in lung cancer incidence for south Asians: a population based register study
}

\author{
Lucy K Smith, Michael D Peake, Johannes L Botha
}

In Britain the incidence of lung cancer among south Asians (Indian, Pakistani, and Bangladeshi) is much lower than in the rest of the population. ${ }^{1}$ In the UK south Asian population, however, it is the commonest cancer for men and the second commonest for women. ${ }^{2}$ Little has been reported on lung cancer trends among south Asians in Britain. We explored trends in lung cancer incidence from 1990 to 1999 in Leicester (22\% of residents classified as south Asian in 1991 census).

\section{Participants, methods, and results}

We identified cases of lung cancer diagnosed in Leicester residents between 1 January 1990 and 31 December 1999 from the Trent Cancer Registry. Ethnicity data were not available for all patients, so we used software assessing forename and surname to classify patients as south Asian or non-south Asian, ${ }^{3}$ with visual inspection of the data to increase accuracy. We assessed deprivation using the Townsend index. The local research ethics committee approved the study.

Population estimates at the level of electoral wards from the 1991 census (categorised by sex, ethnicity, and 5 year age bands) were aggregated by deprivation tertile to calculate lung cancer incidence. We investigated variation in incidence by ethnicity, deprivation, age, and year of diagnosis and any interactions between them using Poisson regression separately for men and women. We calculated the interaction between period of diagnosis (1990-4 or 1995-9) and ethnicity to compare trends over time.

Of the 1902 patients with lung cancer identified, 76 were classified as south Asian (4\%). South Asians were slightly younger than non-south Asians (median age $70.3 v 72.1$ years). After adjusting for differences in age and deprivation, we found lung cancer rates were lower for south Asians than non-south Asians (incidence ratio for men 0.41 (95\% confidence interval 0.31 to $0.54)$, for women 0.32 ( 0.20 to 0.50$)$ ).

The adjusted incidence increased over time for south Asian men but decreased for non-south Asian men $(\mathrm{P}=0.038)$, with an increase in risk of $43 \%$ for south Asian men (incidence ratio for 1990-4 v 1995-9 1.43 (0.84 to 2.44)) and a decrease of $19 \%$ for non-south Asian men (0.81 (0.72 to 0.91)). For non-south Asian men, the decrease in incidence occurred in those from more deprived areas, where lung cancer incidence was higher (see figure). There was no evidence of a trend with deprivation over time for south Asian men.

Patterns for women were different, with slight increases in lung cancer incidence over time for both south Asians and non-south Asians and no evidence of differing patterns over time $(\mathrm{P}=0.489)$. South Asian women had a $50 \%$ increase in risk (1.50 (0.61 to 3.67)), while the increase in risk for non-south Asians was 9\% (1.09 (0.93 to 1.28)). The changes in incidence over time were similar for all levels of deprivation (see figure).
Department of Epidemiology and Public Health, University of Leicester, Leicester LE1 6TP Lucy K Smith research fellow

Glenfield Hospital, Leicester LE3 9QP Michael D Peake consultant physician and lead clinician for lung cancer

Trent Cancer Registry, Weston Park Hospital, Sheffield S10 2SJ Johannes L Botha director

Correspondence to: L K Smith lks1@le.ac.uk

BMJ 2003;326:81-2 

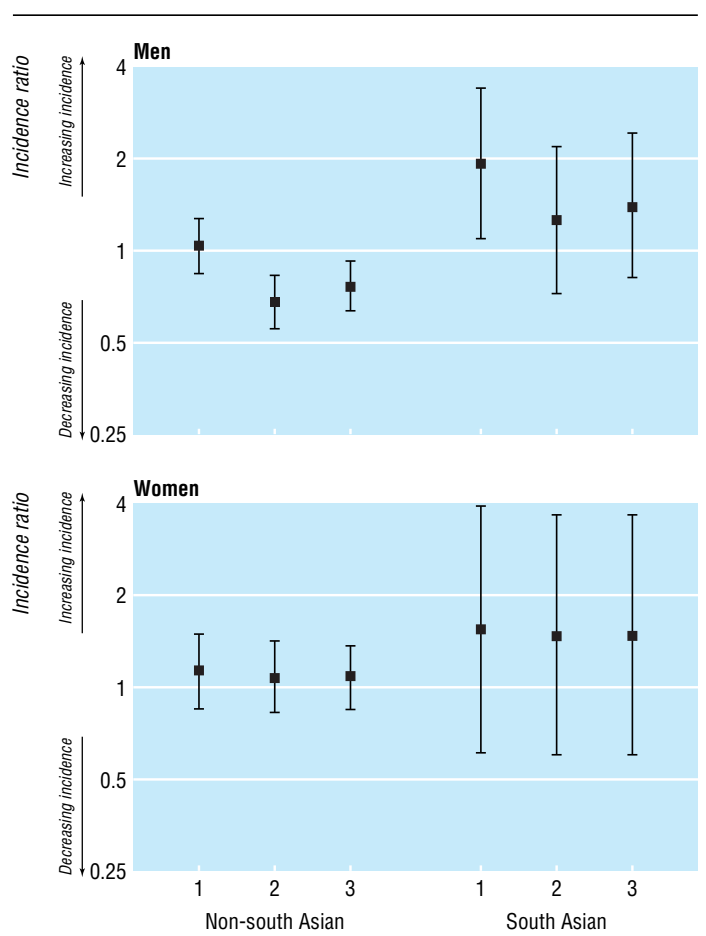

Deprivation tertile (1=least deprived, $3=$ most deprived)

Incidence ratios (95\% confidence intervals) of lung cancer comparing incidence for 1995-9 with that for 1990-4 among south Asian and non-south Asian men and women by deprivation tertile (1=least deprived, $3=$ most deprived). Values (log scale) from Poisson regression models including interactions between time period and deprivation tertile and between time period and ethnicity

\section{Comment}

Our findings confirm lower rates of lung cancer for south Asian men than non-south Asian men but suggest differing trends, with incidence increasing among south Asian men but falling among non-south Asians. There is a tendency to emphasise the importance of cancers such as those of the head and neck among south Asians because they are relatively more common than in the majority UK population. However, Bhopal and Rankin also highlight the need to look at absolute numbers of cancer cases, ${ }^{2}$ which show that lung cancer is the commonest cancer for both south Asian and non-south Asian men. With smoking rates higher among UK south Asians aged 30-49 years than those aged 50-74, ${ }^{4}$ lung cancer prevention is a high priority. Health promotion programmes should target the whole population, and the tendency to dismiss south Asians as "low risk" populations for smoking related disease needs to be revised.

We thank Louise Hollingworth for her help in providing data from the Trent Cancer Registry. Material from Crown Copyright records was made available through the Post Office and the ESRC data archive. We thank Hilda Parker for her comments on the manuscript, and we appreciate the advice of Albert Benghiat, lead clinician for Leicestershire Cancer Services Network.

Contributors: LKS and JLB contributed to the conception and design of the study and secured its funding. LKS analysed the data, and all three authors interpreted the results and wrote the paper. LKS is the guarantor for the study.

Funding: LKS is funded to undertake the research as an MRC/ Trent Region training fellow in health services research.

Competing interests: None declared.

1 Winter H, Cheng KK, Cummins C, Maric R, Silcocks P, Varghese $C$. Cancer incidence in the south Asian population of England (1990-92). BrJ Cancer 1999;79:645-54

2 Bhopal RS, Rankin J. Cancer in minority ethnic populations: priorities from epidemiological data. Br J Cancer 1996;29:S22-32.

3 Cummins C, Winter H, Cheng KK, Maric R, Silcocks P, Varghese C. An assessment of the Nam Pehchan computer program for the identification of names of south Asian ethnic origin. J Public Health Med 1999:21:401-6.

4 Johnson M. Black and minority ethnic groups in England: the second health and lifestyles survey. London: Health Education Authority, 1999.

(Accepted 24 June 2002)

\section{RESEARCH POINTERS}

\section{Platelet responsiveness to aspirin in patients with hyperlipidaemia}

Maribeth Friend, Ivana Vucenik, Michael Miller

Platelet responsiveness to aspirin is reduced in patients with hyperlipidaemia

continued over
Aspirin $325 \mathrm{mg}$ /day reduces the rate of events associated with coronary heart disease. In most people, aspirin produces irreversible inhibition of platelet aggregation, but in a sizeable minority of patients, the degree of platelet aggregation needed to prevent events according to in vitro assessments is not achieved. ${ }^{1}$ Risk factors for coronary heart disease may contribute to aspirin resistance (the inability of aspirin to protect individuals from thrombotic complications), so aspirin may not be cardioprotective in patients with hyperlipidaemia. ${ }^{2}$ We evaluated patients with a range of cholesterol concentrations to determine the impact of hypercholesterolaemia on platelet responsiveness in patients treated with aspirin.

\section{Participants, methods, and results}

Consecutive patients $(n=56)$ were recruited from the University of Maryland Preventive Cardiology

Outpatient Center. The mean (SD) age was 54.3 (11.1) 